\title{
Robust Evolutionary Algorithm Design for Socio-Economic Simulation: Some Comments
}

\author{
Ludo Waltman • Nees Jan van Eck
}

Accepted: 26 May 2008 / Published online: 13 June 2008

(C) The Author(s) 2008

In the original papers by Alkemade et al. (2006, 2007), their evolutionary algorithms (EAs) exhibited an extreme degree of premature convergence when they were run according to approach I. This seemed a quite curious result. We are happy that the correction (Alkemade et al. 2008) makes clear that the degree of premature convergence is much lower than originally reported. There are three further comments that we would like to make on the work of Alkemade et al.

First, Alkemade et al. state that "convergence behavior differs for different values of the EA parameters such as initial density and chromosome length". We would like to emphasize that the behavior of an EA depends on the initial density parameter only in the short run. In the long run, the initial density parameter has no effect on the behavior of an EA. This is because from a mathematical point of view an EA (or, more precisely, a genetic algorithm) is an ergodic Markov chain (e.g., Nix and Vose 1992; Dawid 1996). In the long run, the state of such a Markov chain no longer depends on the initial state. We agree with Alkemade et al. that the behavior of an EA depends on the chromosome length. This is the case not only in the short run but also in the long run. Since the chromosome length is a technical parameter that usually does not have a clear economic interpretation, we regard the dependence of EA behavior on the chromosome length as a disadvantage of the use of EAs for economic modeling.

Second, Alkemade et al. point out that two popular approaches to the use of EAs for economic modeling can yield quite different results. This is a very interesting observation, especially since earlier studies usually simply took one of the two approaches

\footnotetext{
L. Waltman $(\varangle) \cdot$ N. J. van Eck

Econometric Institute, Erasmus School of Economics, Erasmus University Rotterdam, P.O. Box 1738, 3000 DR Rotterdam, The Netherlands

e-mail: lwaltman@few.eur.nl

N. J. van Eck

e-mail: nvaneck@few.eur.nl
} 
without giving any motivation. We believe that the insights provided by Alkemade et al. are useful not only in the field of agent-based computational economics but also in the field of evolutionary game theory. In evolutionary game theory, researchers use the same two approaches that are distinguished by Alkemade et al. That is, researchers either assume that the number of evolving strategies equals the number of players in the game being studied (approach I; e.g., Vega-Redondo 1997) or they assume that the number of evolving strategies exceeds the number of players and that strategies are randomly matched to play the game (approach II; e.g., Kandori et al. 1993; Weibull 1995). The insights provided by Alkemade et al. suggest, for example, that the result of Vega-Redondo (1997), who finds that evolution leads to the Walrasian equilibrium in Cournot oligopoly games, may change if approach II rather than approach I is adopted.

Third, Alkemade et al. argue that approach II is preferable over approach I because the latter approach exhibits premature convergence. We take a different point of view. In our opinion, there are two reasons why approach II need not be preferable over approach I. The first reason is that in the context of economic modeling premature convergence of an EA is not necessarily something undesirable. We believe that the use of EAs for economic modeling needs to be supported by empirical evidence or by evidence from laboratory experiments (e.g., Arifovic 1994; Duffy 2006). From this perspective, whether approach I or approach II is preferable is an empirical issue and depends on the economic problem being modeled. It may be that some problems can best be modeled using approach I while other problems can best be modeled using approach II. The premature convergence observed under approach I may for example be useful for modeling problems characterized by path dependence (e.g., Arthur 1994). The second reason why approach II need not be preferable over approach I has to do with the specific type of EA that was used by Alkemade etal., namely a genetic algorithm with a binary encoding. We believe that the premature convergence observed by Alkemade etal. under approach I depends crucially on their use of a binary encoding. When we replicated the simulations of Alkemade et al. using an evolution strategy (e.g., Beyer 2001), which is a type of EA that does not rely on a binary encoding, we did not observe any premature convergence at all under approach I.

Open Access This article is distributed under the terms of the Creative Commons Attribution Noncommercial License which permits any noncommercial use, distribution, and reproduction in any medium, provided the original author(s) and source are credited.

\section{References}

Alkemade, F., La Poutré, J. A., \& Amman, H. M. (2006). Robust evolutionary algorithm design for socioeconomic simulation. Computational Economics, 28(4), 355-370. doi:10.1007/s10614-006-9051-5.

Alkemade, F., La Poutré, J. A., \& Amman, H. M. (2007). On social learning and robust evolutionary algorithm design in the Cournot oligopoly game. Computational Intelligence, 23(2), 162-175. doi:10.1111/j.1467-8640.2007.00300.x.

Alkemade, F., La Poutré, J. A., \& Amman, H. M. (2008). Robust evolutionary algorithm design for socioeconomic simulation: A correction. Computational Economics.

Arifovic, J. (1994). Genetic algorithm learning and the cobweb model. Journal of Economic Dynamics \& Control, 18(1), 3-28. doi:10.1016/0165-1889(94)90067-1. 
Arthur, W. B. (1994). Increasing returns and path dependence in the economy. University of Michigan Press.

Beyer, H.-G. (2001). The theory of evolution strategies. Springer.

Dawid, H. (1996). Adaptive learning by genetic algorithms. Number 441 in Lecture notes in economics and mathematical systems. Springer.

Duffy, J. (2006). Agent-based models and human subject experiments. In L. Tesfatsion \& K. L. Judd (Eds.), Handbook of computational economics (Vol. 2, pp. 949-1011). Elsevier.

Kandori, M., Mailath, G. J., \& Rob, R. (1993). Learning, mutation, and long run equilibria in games. Econometrica, 61(1), 29-56. doi:10.2307/2951777.

Nix, A. E., \& Vose, M. D. (1992). Modeling genetic algorithms with Markov chains. Annals of Mathematics and Artificial Intelligence, 5(1), 79-88. doi:10.1007/BF01530781.

Vega-Redondo, F. (1997). The evolution of Walrasian behavior. Econometrica, 65(2), 375-384. doi: $10.2307 / 2171898$.

Weibull, J. W. (1995). Evolutionary game theory. MIT Press. 